\section{More Evidence that Math Anxiety is Specific to Math in Young Children: The Correlates of the Math Anxiety Questionnaire for Children (MAQC)}

\author{
Monika Szczygieł*
}

\begin{tabular}{ll}
\hline Received: & 24 February 2020 \\
Revised: $\quad 29$ May 2020 \\
Accepted: $\quad$ 13 June 2020 \\
ISSN: $1307-9298$ \\
Copyright @ IEJEE \\
www.iejee.com
\end{tabular}

DOI: 10.26822/iejee.2020562133

\title{
Abstract
}

Although interest in math anxiety in young children has recently increased, the results of previous studies on math anxiety correlates are inconsistent. The article presents the results of two studies conducted among early school-age learners (6-11 years) where the Math Anxiety Questionnaire for Children (MAQC) was used. The results indicate that the MAQC score (a) positively and moderately/strongly correlates with math anxiety scores obtained with other scales, (b) positively and mainly moderately correlates with general and test anxiety, (c) and negatively and weakly/moderately correlates with math achievement. Negative, weak, and significant relationships between math anxiety and math achievement occur even if general and test anxiety are controlled. Moreover, the results of the group comparison test show that children with a high level of math self-esteem have lower math anxiety than children with medium math self-esteem and this effect is large. Children with medium and high Polish language self-esteem do not differ from each other in math anxiety. It may be concluded that math anxiety in young children is a specific kind of anxiety, and its correlates are similar to those in secondary school-age children, adolescents, and adults.

Keywords: Math Anxiety, Math Achievement, General Anxiety, Test Anxiety, Early School-Age Children

\section{Math Anxiety in Early School-Age Children}

Math anxiety is "a feeling of tension and anxiety that interferes with the manipulation of numbers and the solving of mathematical problems in a wide variety of ordinary life and academic situations" (Richardson \& Suinn, 1972, p. 551). Math anxiety is defined as a specific kind of anxiety that negatively affects math outcomes on various levels of math education (Hembree, 1990). Research conducted among increasingly younger students has led to the discovery that even children starting school feel some level of math anxiety (Carey, Hill, Devine, \& Szűcs, 2017; Cargnelutti, Tomasetto, \& Passolunghi, 2017; Ganley \& McGraw, 2016; Gierl \& Bisanz, 1995; Harari, Vukovic, \& Bailey, 2013; Hill, Mammarella, Devine, Caviola Passolunghi, \& Szűcs, 2016; Jameson, 2013, 2014; Krinzinger, Kaufmann, \& Willmes, 2009; Mutlu, 2019; Ramirez, Gunderson, Levine, \& Beilock, 2013; Ramirez, Chang, Maloney, Levine, \& Beilock, 2016; Vukovic, Kieffer, Bailey, \& Harari, 2013; Young, Wu, \& Menon, 2012; Wu, Barth, Amin, Malcarne, \& Menon, 2012). Although the number of studies on the nature of math anxiety in children has increased, some theoretical issues related to its characteristics remain unclear.

There is insufficient evidence that math anxiety in young children is a specific kind of anxiety. Previous studies on math anxiety specificity mostly test the shared variance of math anxiety with general anxiety defined as an individual's disposition toward worrying about a number of different things, events, behaviors, and competences (Spence, 1997), and with test anxiety defined as an apprehension in situations involving performance evaluation (Putwain \& Daniels, 2010). Some of the studies in young children showed that math anxiety moderately or strongly correlates with general anxiety (Carey et al., 2017; Cargnelutti et al., 2017; Ganley \& McGraw, 2016; Hill at al., 2016; Szczygieł, 2019) and with test anxiety (Carey et al., 2017; Gierl \& Bisanz, 1995). However, other studies reported no such relationship between math anxiety and general anxiety (Cargnelutti et al., 2017; Gierl \& Bisanz, 1995; Wu et al., 2012). Assuming that a significant proportion of math anxiety variance is shared with general and test anxiety, then math anxiety is rather an unspecific manifestation of general or test anxiety. If math anxiety and general and test anxiety are weakly or moderately correlated with each other, this could suggest that math anxiety is a unique construct (Carey et al., 2017; Stöber \& Perkur, 2004).

Furthermore, if math anxiety is a specific type of anxiety, then the scores of various math anxiety scales should be highly correlated with each other and such a relationship should be stronger than the relationship between math anxiety and general and test anxiety. Usually, correlations between various math anxiety measures and both general anxiety and test anxiety are tested; however, the specificity of math anxiety should also be confirmed in other ways. If math anxiety is specific to mathematics, its level should be dependent on math self-esteem (Eden, Heine, \& Jacobs, 2013; Ganley \& McGraw, 2016) rather than language self-esteem, for example. Therefore, children who are good at math should have high math self-esteem and low math anxiety, and their counterparts who are bad at math may have low math self-esteem and a high level of math anxiety (Eden et al., 2013; Szczygieł, 2019). That said, language self-esteem should not affect the level of math anxiety. If the level of math anxiety and the level of self-esteem in academic domains other than math are related to each other, this means that math anxiety is more general than it may be supposed.

Based on previous studies, it can be assumed that math anxiety should be negatively related to math achievement. Most studies involving young children showed a negative correlation between math anxiety and math achievement (Gierl \& Bisanz, 1995; Harari et al., 2013; Jameson 2013; Ramirez et al., 2013, 2016; Wu et al., 2012; Vukovic et al., 2013 - among children with high working memory capacity; Szczygieł, 2019); however, other studies reported no relationship between both variables (Cargnelutti et al., 2016; Krinzinger et al., 2009; Harari et al., 2013; Thomas \& Dowker, 2000). The inconsistent results may be down to the varying validity and reliability of math anxiety measures and the type of mathematical tasks (Cargnelutti et al., 2016; Harari et al., 2013; Krinzinger et al., 2009; Thomas \& Dowker, 2000). Therefore, it can be assumed that if the appropriate measure of math 
anxiety is used, the relationship between math anxiety and math achievement should occur in early school-age children. Moreover, if math anxiety is specific to mathematics, it should be correlated with math achievement - even if general and test anxiety are controlled. However, there is little research that tests these relationships. Some studies show that math anxiety and math achievement are related when general (Ganley \& McGraw, 2016; Hill et al., 2013 - in secondary children) and test anxiety (Gierl \& Bisanz, 1995; Van Mier, Schleepen, \& Van den Berg, 2019 - in girls) are controlled, but others indicate no such relationship (Ganley \& McGraw, 2016; Hill et al., 2013 - in primary children; Van Mier et al., 2019 - in boys). At the same time, previous studies do not test the relationship between math anxiety and math achievement when general and test anxiety were controlled. Therefore, if math anxiety is related to math achievement in young children, even in those cases where general and test anxiety are controlled, this means that math anxiety is uniquely related to math.

Finally, most of the studies on math anxiety in children, adolescents, and adults are conducted among English language samples. However, due to international differences in the organizational system of mathematical education, it is justified to follow the data obtained from cultural backgrounds other than the West (Browne, Ortiz-Padilla, \& Soto-Varela, 2020). If subsequent studies provide further arguments on the specificity of math anxiety and its detrimental effect on math achievement in young children, more attention should be paid to the identification of its sources and the prevention of future math anxiety development.

\section{Present Study}

Since the results of previous studies on the specificity of math anxiety are inconsistent or insufficient, the main purpose of this article is to provide additional data on the nature of math anxiety in young children. In the paper, the results of two studies are presented which were conducted in a sample of Polish first- to third-grade children. It was assumed that if math anxiety is a specific kind of anxiety, the math anxiety measure (MAQC) should be positively and highly correlated with other measures of math anxiety, and positively and moderately correlated with general and test anxiety. Moreover, math anxiety should be negatively related to math achievement even if general and test anxiety are controlled. Furthermore, children with high math self-esteem in comparison to those with low math self-esteem should be less math-anxious; however, no differences in math anxiety should be observed between children with a low and high level of Polish language self-esteem.

\section{Method}

\section{Participants}

The results of two studies in early school-age children are presented. The children that participated in the project attended public primary schools in Krakow (Poland). In the first phase of the school's enrollment for the study, schools were randomly selected for examination from the list of all schools in the city. However, the participation of children in it depended on the decision of the head of school, parents, and the children themselves. Some headmasters and parents did not respond to the request or did not give permission for the research.

The first study was conducted in nine schools at the end of the first, second, and third grade in a cross-sectional plan (Study 1). The schools occupied different positions in the ranking of schools in the city from the top to the bottom of the list. The research was conducted in a group of 241 pupils: 46 children (23 girls) from the first grade (mean age 7 years and 3 months, range 6.1-8.3 years), 101 children (60 girls) from the second grade (mean age 8 years and 2 months, range 7.1-9.3 years), and 94 children (51 girls) from the third grade (mean age 9 years and 4 months, range $8.0-11.2$ years). The data about education, income, and occupation were collected during a parent-teacher conference. The socioeconomic status of most children's families was moderate or high.

The second study was conducted in twelve primary schools (other than those in the first study). The schools occupied different positions in the ranking of schools in the city (from the top to the bottom of the scale). The study is longitudinal and started at the beginning of the first grade and continues up to today (Study 2). However, the study presents the results collected at the end of the second grade because the MAQC scale was used then. Two hundred and thirty-one second-grade children (110 girls) took part in the measurement. The mean age of children at the end of the second grade was around 8-9 years. The socioeconomic status of the families was assessed based on education, income, and occupation. Most of the children came from families with a medium or high socioeconomic status.

\section{Measures}

\section{Math anxiety}

The Math Anxiety Questionnaire for Children (MAQC) was developed for measuring general math anxiety in young children. The scale is based on the Mathematics Anxiety Scale in Young Children (MASYC; Harari et al., 2013) and the Scale for Early Mathematics Anxiety (SEMA; Wu et al., 2012). The MASYC is three-dimensional (negative reactions, numerical confidence, and worry), whilst the SEMA consists of two factors (numerical processing anxiety, situational and performance anxiety). First, it was checked whether these scales could be adapted to the Polish early school education environment. Both scales were translated into Polish, back-translated, proofread, and tested in pilot sessions. Following a pilot research that used both scales in a Polish group of early school-age children, a significant number of changes were needed to be made to the MASYC and the SEMA. Firstly, the items were not adequate for the level of the children's language skills (especially that which was related to physiological anxiety). Secondly, the mathematics curriculum in Poland differs from the US curriculum, so math-related questions were not valid and were removed. Finally, the response scale used in the MASYC and the SEMA (a four- or five-point scale) was too complex for children from first to third grade.

The significant modifications made to the MASYC and the SEMA required a new scale to be actually created. Based on the problems described above, the items' reliability, and item content analyses, selected questions from both scales were used in the final version of the measurement. These items concerned math anxiety related to performing math activities, and the final version of the scale was intended to measure general math anxiety related to performing math activities. To improve the validity and reliability of measurement, some new items were added to the scale. The MAQC content follows the definition of math anxiety by Richardson and Suinn (1972). They described math anxiety as a type of anxiety that concerns solving math problems in various academic situations. The final version of the scale consisted of twelve items (see details in Appendix). The response scale was limited to a three-point scale $(0-$ no, 1 - a little, 2 -yes), which in turn enabled simple answers from children. The higher the MAQC score was, the higher level of math anxiety related to performing math activity was indicated. To eliminate the impact of the children's varying reading skills, the instructions were read aloud by the researcher.

The structure of the scale was tested by exploratory (EFA) and confirmatory (CFA) factor analyses using the combined data from the cross-sectional and longitudinal studies. The data set was divided into two parts that were equal in terms of the type 
Table 1. EFA and CFA in the MAQC

\begin{tabular}{|c|c|c|c|c|c|}
\hline & $n=368$ & Sample A & $n=184$ & Sample B & $n=184$ \\
\hline & $M(S D)$ & Item-scale correlations & $\beta$ EFA & Item-scale correlations & $\beta$ CFA \\
\hline 1 & $.39(.66)$ & .48 & .52 & .54 & .56 \\
\hline 2 & $.67(.79)$ & .63 & .61 & .64 & .74 \\
\hline 3 & $.41(.70)$ & .58 & .61 & .49 & .55 \\
\hline 4 & $.53(.73)$ & .64 & .70 & .62 & .66 \\
\hline 5 & .72(.82) & .65 & .67 & .54 & .52 \\
\hline 6 & $.09(.35)$ & .56 & .82 & .46 & .80 \\
\hline 7 & $.25(.55)$ & .52 & .59 & .48 & .55 \\
\hline 8 & . $16(.45)$ & .28 & .41 & .36 & .37 \\
\hline 9 & $.54(.72)$ & .57 & .57 & .56 & .55 \\
\hline 10 & $.52(.73)$ & .61 & .61 & .55 & .60 \\
\hline 11 & . $12(.40)$ & .51 & .74 & .48 & .65 \\
\hline 12 & $.30(.59)$ & .55 & .58 & .47 & .47 \\
\hline \multicolumn{6}{|l|}{ Model Summary } \\
\hline \multicolumn{2}{|c|}{ Recommended value (Hu \& Bentler, 2009) } & & \multirow[t]{2}{*}{ Obtained value } & \multicolumn{2}{|r|}{ Obtained value } \\
\hline $\mathrm{CFI}$ & $>.90$ & & & & .95 \\
\hline TLI & $>.95$ & & .70 & & .93 \\
\hline SRMR & $<0.08$ & & .09 & & 13 \\
\hline RMSEA $[90 \% \mathrm{Cl}]$ & $<0.06$ & & $.15[.14, .17]$ & & $.07[.04, .09]$ \\
\hline
\end{tabular}

Note: All item-scale correlations and the regression path were significant on $p<.001$. CFI - Comparative Fit Index, TLI - Tucker-Lewis Index, SRMR - Standardized Root Mean Square Residual, RMSEA - Root Mean Square Error of Approximation.

of study, grade year, and gender $\left(n_{1}=184, n_{2}=184\right)$. The analyses were conducted in $\mathrm{R}$ packages: psych (EFA, Rewelle, 2019) and lavaan (CFA, Rosseel, 2012).

In the first step of the EFA, a parallel analysis was run to extract the actual number of dimensions. Based on the parallel analysis scree plot and item content, one factor was extracted. Then, the principal axis method with the oblimin rotation was applied. Analysis was run on the polychoric correlation matrix because of the ordinal variables. All statistical assumptions were met to conduct EFA: Bartlett's test of sphericity $\chi_{(66)}^{2}=747.76 ; p<.001 ; \mathrm{KMO}=.82$; matrix determinant $=.08$. The extracted factor explained $39 \%$ of variance, which is a comparable result to the SEMA (38.29\% explained by two factors, Wu et al., 2012) and the MASYC (41.34\% explained by three factors, Harari et al., 2013). The model fit indices are below cut-off (especially TLI and RMSEA); however, the item-factor loadings ranged .24-.58, which is acceptable in social sciences (Costello \& Osborne, 2005). Moreover, the item-scale correlations varied from $r=$ .28 to $r=.63, p<.001$, which indicates that the items are associated with the overall results in the same direction and at similar levels (see Table 1).

To verify the fit of the unidimensional solution, CFA was performed in the second sample. Mardia's test shows that the assumption of multivariate normality was violated (skewness 2197.02, $p<.001$, kurtosis 29.22, $p<.001$ ). Because of this and because of the ordinal characteristic of the variables, the Diagonally Weighted Least Squares estimator (DWLS) on the polychoric correlation matrix was used (Mîndrilă, 2010). The model does not fit the data very well $\left(\chi^{2}{ }_{(54)}=\right.$ 96.44; $p<.001$ ), but the model fit indices are acceptable (see Table 1). The value of the CFI indicates a good model fit, the TLI and the RMSEA values are on the border of cut-off and indicate a reasonably good model fit, but the SRMS is unsatisfactory. This relatively higher value may be, however, explained by the sample size. The standardized difference between the observed correlation and the predicted correlation is greater for a small number of observations (Nye \& Drasgow, 2011). Although the model fit is not perfect, the factor loadings ranged .37-.80, and these values are prop- er (Costello \& Osborne, 2005). Additionally, the item-scale correlations confirm that the scale is consistent $(r=.36-.64)$.

The internal consistency of the MAQC calculated for the whole group is $\alpha=0.77(n=368)$, and the test-retest reliability is $r=.56, p<.001, n=55$. Therefore, the reliability of the MAQC is very satisfactory.

The modified Abbreviated Math Anxiety Scale for Elementary School Children (mAMAS-E, Szczygieł, 2019) is based on the mAMAS (Carey et al., 2017) and is intended for early school-age children. The scale consists of two subscales: learning and testing math anxiety and has nine items and a three-point response scale. The higher the mAMAS-E scores were, the higher the levels of math anxiety (general, learning, and testing) were indicated. To check the structure of the scale in the tested sample, CFA was applied. Mardia's test shows that the assumption of multivariate normality was violated (skewness 3238.46, $p<.001$, kurtosis $61.18, p<$ $.001, n=419$ ). Additionally, the variables are three-categorical. Therefore, the DWLS estimator was applied and analysis was conducted on the polychoric correlation matrix (Mîndrilă, 2010). The model fits the data very well: $\chi_{(26)}^{2}=36.62 ; p=$ .08 , and the model fit indices are very satisfactory: $\mathrm{CFI}=.99$, $\mathrm{TLI}=.99, \mathrm{RMSEA}=.03[90 \% \mathrm{Cl} 0, .05]$, SRMR $=.07$. The factor loadings ranged .59-.79 (math learning anxiety) and .55-.73 (math testing anxiety); they are both very well (Costello \& Osborne, 2005). The internal consistency reliability of the math learning anxiety scale is $\alpha=.59$, and of the math testing anxiety scale is .71. Stratified alpha calculated for mAMAS-E total is .78. The reliability of the total and the math testing anxiety scores is plausible; however, the internal consistency of the math learning anxiety scale is below expected. The relatively low reliability may be explained by the shortness of the scale and the low variance of the results obtained in a small number of categories in the response scale.

\section{General Anxiety}

The Revised Children's Manifest Anxiety Scale (RCMAS, Reynolds \& Richmond, 1978) measures general anxiety and consists of a lies scale and three subscales: physiological anxiety 
(RCMAS-P), worry/oversensitivity (RCMAS-W), and social concerns/concentrations (RCMAS-S). The Polish language version of the scale was prepared in accordance with the back-translation procedure and tested in other studies. The scale has 37 items, to which the children answer yes/no. The higher score in the RCMAS was, the higher level of anxiety was indicated. The internal consistency reliability of the RCMAS is $\alpha=.69$ for physiological anxiety, $\alpha=.69$ for worry, and $a=.75$ for social anxiety $(n=57)$. Stratified Cronbach's a for total score is .89 The reliability of the scales is acceptable. The small number of collected observations does not allow for the confirmation of the scale structure in the study.

The Short Revised Children's Manifest Anxiety Scale (sRCMAS, Stark \& Laurent, 2001) measures general anxiety. Stark \& Laurent (2001) extracted seven items from the RCMAS; they identified them as unique measures of anxiety (irrespective of depression). The scale was prepared in accordance with the back-translation procedure, improved in the Polish language, and adapted to the Polish environment. The response scale on which children assessed the level of their anxiety consists of three categories (0 - no, 1 - a little, 2 - yes). The higher the sRCMAS score was, the higher level of general anxiety was indicated. Based on the authors' remarks and items' content, the scale was assumed to be unidimensional. To check the structure of the scale, CFA was conducted $(n=203)$. Because Mardia's test reveals multivariate nonnormality (skewness $186.55, p<.001$, kurtosis $2.11, p<.05$ ) and the response scale is ordinal, the analysis was conducted with the DWLS estimator and the polychoric correlation matrix (Mîndrilă, 2010). The model significantly deviates from the data $\left(\chi_{(26)}^{2}=186.69 ; p<\right.$ $.001)$, and the model fit indices are on the border of acceptance: $\mathrm{CFI}=.88, \mathrm{TLI}=.83, \mathrm{RMSEA}=.06[90 \% \mathrm{Cl} .05, .08], \mathrm{SRMR}=$ .12. Although the model fit is not excellent, the factor loadings in the model vary from .40 to .74 and are acceptable (Costello \& Osborne, 2005). The internal consistency of the scale is also plausible: $\alpha=.70$

\section{Test Anxiety}

Test anxiety in the children was measured by the Children's Test Anxiety Scale (CTAS, Wren \& Benson, 2004). The CTAS has 30 items and three subscales: thoughts, off-task behaviors, and autonomic reactions; however, in the present study, only the thoughts subscale (CTAS-T; consisting of 13 items) was used. The CTAS-T was translated into Polish, back-translated, and subsequently improved. The scale is a four-point measurement tool: children described their feelings when taking a test from 1 (almost never) to 4 (almost always). As the number of points in the test increases, the level of test anxiety grows. The structure of the CTAS-T was checked using CFA $(n=249)$. Mardia's test indicates multivariate nonnormality (skewness $1241.90, p<.001$, kurtosis 18.55, $p<.001$ ), and the variables are ordinal; therefore, the DWLS estimator and the analysis on the polychoric correlation matrix were run (Mîndrilă, 2010). Although the model significantly deviates from the data $\left(\chi^{2}{ }_{(26)}=\right.$ 128.69; $p<.001)$, the model fit indices are very satisfactory: $\mathrm{CFI}=.98, \mathrm{TLI}=.99, \mathrm{RMSEA}=.06[90 \% \mathrm{Cl} .05, .08], \mathrm{SRMR}=.08$. The factor loadings ranged .38-.80 and are proper (Costello \& Osborne, 2005). The internal consistency reliability of the CTAS-T is appropriate: $\alpha=.86$.

\section{Math and Polish Language Self-esteem}

In order to divide children into groups, they were asked questions about their Math (MSE) and Polish (PSE) self-esteem. Children were asked the following questions: "Are you good at Math? Yes, a little, or no?" and "Are you good at Polish? Yes, a little, or no?". Children who answered "yes", "a little", and "no" were assigned to the group "high self-esteem", "moderate self-esteem", and "low-self-esteem,", respectively.

\section{Math Achievement}

Because no standardized math knowledge tests for early school-age children were available in Poland, the tasks of my own design were used to measure math achievement (MATH) in both studies. I prepared the tasks in cooperation with a mathematician. The main objective of the test construction was to prepare the representative sample of mathematical tasks in accordance with the core curriculum for elementary schools and educational materials recommended by the Polish Ministry of Education. No dimensions of the constructed tasks were assumed.

The preparation of the tasks in the cross-sectional study was as follows. Initially, twenty tasks were prepared for each grade year, and each task consisted of several examples. The properties of item-content and the instructions were rated by a team consisting of several psychologists, an early education teacher, and a mathematician. After improving the test, two pilot sessions were conducted in individual meetings with twenty-one children. The pilot studies allowed me to determine the level at which children understood the instructions, improve the way with which children's answers were rated, and ascertain the level of difficulty in the tasks and their approximate solving time. Finally, eleven complex and representative tasks were selected for the final version of the test. The mathematical test preparation procedure in the longitudinal study was analogous to the one used in the cross-sectional study. Most of the tasks from the first study were reused; however, more examples were added to improve the validity and reliability of the children's math skills assessment.

MATH-1, MATH-2, and MATH-3 were used in the cross-sectional study, MATH-II in the longitudinal research. The following mathematical areas were measured in the first- to third-grade children: MATH-1 - knowledge of numbers, counting, addition, and subtraction, discovering rules, knowledge of money, knowledge of geometric figures, and reading a tape measure; MATH-2/MATH-II - addition and subtraction, multiplication and division, reading a tape measure, spatial orientation, discovering rules, and clock reading; MATH-3 - addition and subtraction, multiplication and division, reading a tape measure, discovering rules, clock reading, and knowledge of dates and money.

In both studies, mathematical tasks were performed by the children themselves, but instructions were read aloud by the researcher to eliminate the impact of the children's varying reading skills. The children completed the mathematical test in 20-40 minutes. In the cross-sectional study, the children could score a maximum of 36 points, and in the longitudinal study 62 .

The psychometric properties of the tests were ascertained. All correlations between mathematical tasks and whole scores in math tests are weak/moderate/strong, positive, and significant $(p<.01)$ : MATH-1 $r=.39-.69$, MATH-2 $r=.29-.71$, MATH-3 $r=.32-.74$, MATH-II $r=.29-.61$. The scale consistency was also confirmed by the satisfactory reliability of the math achievement tasks: MATH-1 $a=.80$, MATH-2 $a=.83$, MATH-3 $\alpha=.89$, MATH-II $a=.91$. Additionally, the level of difficulty for mathematical tasks in each grade year was calculated by the ratio of points actually scored by all children to the maximum number of points that could be obtained. The average level of difficulty for math tasks in study 1 is .77, .71, and .71 for first, second, and third grade, respectively, and .69 in study 2 . In accordance with the assessment of Janowicz (2017), the tasks can be referred to as "easy" or "moderately difficult".

\section{Procedure}

Both studies were conducted in public schools in Krakow after ethical permission had been obtained from the Scientific Research Ethic Committee of the Institute of Psychology, Jagiello- 
nian University of Krakow and approval given from the head of each school and children's parents. The cross-sectional study consisted of two meetings at the end of the school year. The first test session was in April-May 2017, and children were checked in general anxiety (RCMAS), math anxiety (MAQC, mAMAS-E), and math self-esteem (MSE). The second test session was conducted in May-June 2017, and children were tested in math performance (MATH-1, MATH-2, and MATH-3). Children from the longitudinal study were tested at the end of second grade in May and June 2019. They were surveyed in math anxiety (MACQ, mAMAS-E), general anxiety (sRCMAS), test anxiety (CTAS-T), math self-esteem (MSE), Polish language self-esteem (PSE), and math achievement (MATH-II).

Children were surveyed in individual meetings with a research assistant. Each time, children were informed about the purpose of the study, the possibility to refuse to answer questions, and the possibility to withdraw from the study at any time. To eliminate the influence of children's reading skills on the level of their instruction comprehension, all instructions were read aloud by the researcher. Answers about general anxiety, test anxiety, math anxiety, and math and Polish self-esteem were written down by the researcher on the answer card, while solutions to mathematical problems were written on the cards by the children themselves. The average time of the test session lasted 20-45 minutes.

\section{Results}

The analyses were conducted in PS IMAGO PRO 5.1. The results obtained in the two studies are presented together because the collected data are complementary and based on the same tasks and the same age group. The effect size of group comparison was calculated by the calculator of Lenhard \& Lenhard (2016).

Firstly, the descriptive statistics of the MAQC were calculated. The MAQC distribution is right-skewed and deviates from normality (skewness $=1.23$, kurtosis $=1.56, W=.89$, $p<.001)$. The mean MAQC score is low $(M=.39, S D=.34)$; however, both those who feel no math anxiety or are very math-anxious (range $0-1.83$ ) could be found in the sample. The mean score of math anxiety in girls $(M=.44, S D=.38, n=$ $193)$ is higher than in boys $(M=.31, S D=.34, n=176)$ and this gap is small/medium $\left(t_{(367)}=-2.80 ; p<.01 ; d=.36\right)$.

In the second step of the analysis, the specificity of math anxiety was checked by a series of Pearson's correlation tests. It was tested whether the math anxiety measured by the MAQC is related to another measure of math anxiety, general anxiety, test anxiety, and math achievement (see Table 2).

The results from both studies show that the math anxiety measured by the MAQC positively and moderately/strongly correlates with total, math learning, and math testing anxiety. The MAQC score positively and mainly moderately correlates with general anxiety and moderately with test anxiety. Negative and weak/moderate relationships were observed between the MAQC score and math achievement. The results are mostly consistent with those formulated in the assumptions (see: introduction).

Afterward, additional analyses were conducted to check whether the MAQC score is related to math achievement even when general anxiety and test anxiety are controlled (see Table 3).

In study 1, it was tested whether the MAQC score is related to the MATH score calculated together for children from first to third grade. The combination of data was justified because of: (a) relatively few observations in each grade year; (b) non-significant differences in the average result in MATH in each grade year; and (c) almost the same difficulty level of mathematical tasks in each grade year. The results indicate a significant, negative, and moderate correlation between math anxiety and math achievement when general anxie-

Table 2. Zero-order Correlations with the MAQC Score

\begin{tabular}{|c|c|c|c|c|c|c|}
\hline & Study & Task & N & Mean $(S D)$ & MAQC & Effect size interpretation \\
\hline \multirow{3}{*}{ Math anxiety } & \multirow{3}{*}{$1 \& 2$} & mAMAS-E Total & 284 & $.34(.34)$ & $.66^{* \star \star}$ & Strong \\
\hline & & mAMAS-E Learning & 284 & $.18(.29)$ & $.59 * * *$ & Moderate/Strong \\
\hline & & mAMAS-E Testing & 284 & $.53(52)$ & $.56^{\star \star \star}$ & Moderate \\
\hline \multirow{5}{*}{ General anxiety } & \multirow{4}{*}{1} & RCMAS & 57 & $.40(23)$ & $.60^{* \star *}$ & Moderate/Strong \\
\hline & & RCMAS-P & 57 & $.37(24)$ & $.48^{* * *}$ & Moderate \\
\hline & & RCMAS-W & 57 & $.36(26)$ & $.57^{* * *}$ & Moderate \\
\hline & & RCMAS-S & 57 & $.33(30)$ & $.49 * * *$ & Moderate \\
\hline & 2 & SRCMAS & 119 & $.68(.48)$ & $.47^{* \star *}$ & Moderate \\
\hline Test anxiety & 2 & CTAS-T & 127 & $2.03(.61)$ & $.47^{* \star *}$ & Moderate \\
\hline \multirow{4}{*}{ Math achievement } & \multirow{3}{*}{1} & MATH-1 & 46 & $27.75(4.98)$ & $-.40^{* *}$ & Weak/Moderate \\
\hline & & MATH-2 & 101 & $25.91(6.06)$ & $-.39 * * *$ & Weak/Moderate \\
\hline & & MATH-3 & 93 & $25.67(7.33)$ & $-.37^{* * *}$ & Weak/Moderate \\
\hline & 2 & MATH-II & 127 & $42.83(9.88)$ & $-.38 * \star \star$ & Weak/Moderate \\
\hline
\end{tabular}

Note: ${ }^{*} p<.05 ;{ }^{* *} p<.01 ;{ }^{* * *} p<.001$. The effect size is provided based on Evans' proposal (1996): $r<.20$ very weak, $.20-.39$ weak, $.40-.59$ moderate, $.60-.79$ strong, $>.80$ very strong correlation.

Table 3. Partial Correlations between the MAQC Score and Math Achievement (General Anxiety and Test Anxiety as Covariates)

\begin{tabular}{|c|c|c|c|c|c|}
\hline Study 1 & & & Study 2 & & \\
\hline Controlled by & \multirow{5}{*}{ MATH 1-3 } & MAQC & Controlled by & \multirow{5}{*}{ MATH-II } & MAQC \\
\hline RCMAS & & $-.31^{*}$ & sRCMAS & & $-.33^{* * *}$ \\
\hline RCMAS-P & & $-.34^{\star}$ & CTAS-T & & $-.26 * *$ \\
\hline RCMAS-W & & $-.35^{* *}$ & SRCMAS \& CTAS-T & & $-.28 * *$ \\
\hline RCMAS-S & & $-.30^{*}$ & & & \\
\hline
\end{tabular}

Note: ${ }^{*} p<.05 ;{ }^{* *} p<.01 ;{ }^{* * *} p<.001$; Study 1: $n=55$, study 2: $n=116-125$. All correlations are weak in accordance to Evans' proposal (1996). 
ty is controlled. The type of general anxiety does not change the results. In study 2 , it was checked whether math anxiety is related to math achievement when general anxiety and test anxiety are controlled separately and together. The results show a significant, negative, and weak relationship between the MAQC score and math achievement in each case. Therefore, the results from both studies confirm that math anxiety is related to math achievement even when general and test anxiety are controlled.

Finally, it was planned to compare children with low and high levels of math and Polish language self-esteem; however, in the tested sample, there were only a few children with low levels of math self-esteem. Because of that, a comparison between children with moderate and high levels of math and Polish self-esteem was performed. Children with moderate math self-esteem $(M=.60, S D=.35, n=53)$ feel stronger math anxiety in comparison to those with high levels of math self-esteem $(M=.29, S D=.29, n=67)$ and the difference is large $\left(t_{(118)}=5.34\right.$ $p<.001 ; d=.97)$. However, a lack of statistically significant differences between children with a moderate $(M=.44, S D=.42$, $n=46)$ and high $(M=.48, S D=.39, n=69)$ level of Polish language self-esteem was noted $\left(t_{(113)}=-.65 ; p=.51 ; d=.10\right)$.

\section{Discussion}

Math anxiety is considered an important predictor of mathematical skills in school-age children, adolescents, and adults (Dowker, Sarkar, \& Looi, 2016; Zhang, Zhao, \& Kong, 2019). In recent years, it was observed that children starting school also display some syndrome of math anxiety (Ganley \& McGraw, 2016; Jameson, 2013; Ramirez et al., 2013). Since children in first to third grade do not have many math-related experiences, it prompts questions about the specificity of math anxiety in young children. Can we explain math anxiety by general anxiety or test anxiety? Does math anxiety negatively affect children's math performance? If yes, does the effect occur when general and test anxiety levels are controlled? Since math anxiety in young children has been studied relatively recently, more evidence needs to be gathered for the specificity of math anxiety in this age group. The answer to this gap is two complementary studies conducted among children from first to third grade.

The results of both studies show that math anxiety is specific to mathematics and cannot be identified with general or test anxiety. First of all, it was shown that math anxiety measures are moderately or strongly correlated with each other and such correlations were mostly stronger than the relationships between the MAQC score and general and test anxiety. Although math anxiety shares a substantial part of variance with general and test anxiety, these constructs are not correlated strongly enough with each other to conclude that they are identical.

Secondly, the level of math anxiety was dependent on the level of math self-esteem but not on the level of Polish language self-esteem. It turns out that young children can properly assess their own school subject skills. In this domain, self-esteem is connected to the level of their anxiety toward school subjects. If math anxiety was not specific to mathematics, its level would not only depend on self-assessment of their mathematical skills (Goetz, Cronjaeger, Frenzel, Ludtke, \& Hall, 2010; Szczygieł, 2019), but also language skills.

Moreover, research results provide evidence that math anxiety is negatively and moderately related to math achievement in children from first to third grade, which means that such a relationship occurs irrespective of the type of math tasks. Therefore, the obtained results provide more evidence that math anxiety is negatively related to math achievement in young children (Gierl \& Bisanz, 1995; Harari, 2013; Jameson, 2013; Ramirez et al., 2013, 2016; Szczygieł, 2019; Vukovic et al., 2013; Wu et al., 2012). Furthermore, the negative relationship between math anxiety and math achievement persists when general anxiety and test anxiety are separately and simultaneously controlled. These results clearly demonstrate that math anxiety in young children is something more than a disposition toward feeling anxiety in everyday or test situations (Ganley \& McGraw, 2016; Gierl \& Bisanz, 1995; Hill et al., 2013; Van Mier et al., 2019). Therefore, the research results indicate that math anxiety in young children is similar to that in older children, adolescents, and adults, and is a specific kind of anxiety (Ashcraft, 2019; Hembree, 1990; Ma, 1999).

Similar to other research results, the study shows that the average level of math anxiety in the studied group was low, but there were some children with a high level of math anxiety (Carey et al., 2017; Cargnelutti et al., 2017; Ganley \& McGraw, 2016; Krinzinger et al., 2009; Ramirez et al., 2016; Wu et al., 2012; Young et al., 2012). The results fit Zhang et al.'s math anxiety development model (2019), which assumes that low levels of math anxiety at the beginning of education increase throughout the years, peak in high school and then slowly decrease, while not disappearing completely in adulthood. Because math anxiety predicts the avoidance of math-related activities (Choe, Jennifer, Rozek, Berman, \& Beilock, 2019), it is necessary to know the sources of math anxiety formation and development. Among the factors contributing to children's math anxiety are individual and environmental factors such as genetic factors (Wang et al., 2019) and factors related to teachers and parents (Maloney et al., 2015; Szczygieł, 2020). Indeed, previous studies show that children's math anxiety is underlined by anxieties related to making mistakes, bad grades, dissatisfaction shown by teachers and parents, and ridicule in front of the whole class. However, because of little support for the hypothesis that teaching methods or teachers' and parents' own math anxiety directly or indirectly affects children's math anxiety (Beilock, Gunderson, Ramirez, \& Levine, 2010; Maloney, Ramirez, Gunderson, Levine, Beilock, 2015; Soni \& Kumari, 2017; Szczygieł, 2020), further research is needed in this area.

Moreover, the present research results show that girls are more math-anxious than boys, which is in accordance with the results obtained in some studies (Carey et al., 2017; Griggs, Rimm-Kaufman, Merritt, \& Patton, 2013; Hill et al., 2016; Szczygieł, 2019), but contradictory to other reports (Gierl \& Bisanz, 1995; Harari et al., 2013; Jameson, 2014; Kucian et al., 2018; Ramirez et al., 2013; Young et al., 2012). The gender gap in math anxiety was also discussed in studies among secondary school learners and adults. These studies either indicated that females have higher math anxiety levels than males (NúñezPeña, Suárez-Pellicioni, \& Bono, 2016) or demonstrated no differences in math anxiety levels between males and females (Birgin, Baloglu, Catlioglu, \& Gurbuz, 2010; Devine, Fawcett, Szücs, \& Dowker, 2012). Both theorists and practitioners may find it vital to determine whether gender differences in math anxiety occur or not in young children. One of the purported reasons for women "escaping" from STEM sciences is math anxiety (Choe et al., 2019). In accordance with the obtained results, math anxiety starts at an early school age and is higher among girls than boys. Therefore, it seems that being female is a risk factor for the development of math anxiety; however, more studies are needed in this area.

Finally, methodological issues should be noted. One of the limitations to these studies is the generalizability of the obtained results on the early school-age children population. Both studies were conducted in children living in a big city and brought up in families with a moderate/high socioeconomic status. The studies involved minors, which means that permission from headmasters and parents was needed to complete them. It is possible that already at the stage of obtaining consent there was a bias in the selection of people interested in participation. Parents interested in their child's education participated in a parents-teacher conference and agreed to have their children examined while less engaged parents refused 
consent to the child's participation in the study. This hypothesis is supported by the relatively high socioeconomic status of the children's families and the pupils' high level of math performance. The second important issue concerns the measurement of math, general, and test anxiety, as well as math achievement. Some of the measures used in the study have very well psychometric properties, but others need some improvements and further development. Especially, a greater sample size is needed if the structure of the measurement is tested. Nye and Drasgow (2011) suggest that the CFA model should be run on around 800-1000 observations if the Weighted Least Squares estimator is applied. This is particularly important if correlations between items are weak or moderate (Kenny, 2015). Moreover, Nye and Drasgow (2011) indicate that model fit assessment criteria should be stricter if the DWLS is used instead of the ML estimator. Although the issues of psychological assessment in young children were discussed in detail in other papers (e.g. Ganley \& McGraw, 2016; Stark \& Laurent, 2001; Szczygieł, 2019), it should be noted that problems with the valid and reliable measurement of emotions in early school-age children are a common phenomenon (Cargnelutti et al., 2016; Harari et al., 2013; Krinzinger et al., 2009; Thomas \& Dowker, 2000). To date, over a dozen scales measuring general, test, and math anxiety have been developed; however, researchers are still working to develop a suitable measurement tool for youngest children.

\section{Conclusions}

The obtained results show that math anxiety in young children is a specific kind of anxiety. Math anxiety may be partially explained by general and test anxiety; however, this cannot be identified. Math anxiety is related to math achievement and math self-esteem in early school-age children, even if general and test anxiety are controlled together. The study confirms the specificity of math anxiety but leads to the formulation of further questions. Girls exhibit higher math anxiety levels than boys, which raises the question why that is the case. Moreover, although the characteristics of math anxiety in early school-age children are similar to the nature of math anxiety in older children, adolescents, and adults, further studies on math anxiety in young children are needed to establish the sources, development, and mechanism of action of math anxiety on math achievement.

\section{Acknowledgement}

I would like to thank all those involved in the project: researchers, school principals, teachers, parents, and pupils. This work was supported by the National Science Centre (Poland; grant number 2015/19/N/HS6/00791).

\section{References}

Ashcraft, M. (2019). Models of math anxiety. In: I. C. Mammarella, S. Caviola, \& A. Dowker (Eds.), Mathematics anxiety. What is known an what is still to be understood (pp. 1-19). London and New York: Routledge.

Beilock, S. L., Gunderson, E. A., Ramirez, G., \& Levine, S. C. (2010). Female teachers' math anxiety affects girls' math achievement. Proceedings of the National Academy of Sciences, 107(5), 1860-1863. doi: 10.1073/ pnas.0910967107

Birgin, O., Baloğlu, M., Çatlıoğlu, H., \& Gürbüz, R. (2010). An investigation of mathematics anxiety among sixth through eighth grade students in Turkey. Learning and Individual Differences, 20(6), 654-658. doi: 10.1016/j.lindif.2010.04.006
Browne, J. L., Ortiz-Padilla, M., \& Soto-Varela, R. (2020). Does Mathematical Anxiety Differ Cross-Culturally? Journal of New Approaches in Educational Research, 9(1), 126-136. doi: 10.7821/naer.2020.1.464

Carey, E., Hill, F., Devine, A., \& Szűcs, D. (2017). The modified Abbreviated Math Anxiety Scale: A valid and reliable instrument for use with children. Frontiers in Psychology, 8(11).

Cargnelutti, E., Tomasetto, C., \& Passolunghi, M. C. (2017). How is anxiety related to math performance in young students? A longitudinal study of grade 2 to grade 3 children. Cognition and Emotion, 31(4), 755764. doi: 10.1080/02699931.2016.1147421

Choe, K., Jenifer, J. B., Rozek, C. S., Berman, M., \& Beilock, S. L. (2019). Calculated avoidance: Math anxiety predicts math avoidance in effort-based decision-making. Science Advances, 20, 5(11), eaay1062. doi: 10.1126/ sciadv.aay1062.

Costello, A. B., \& Osborne, J. W. (2005). Best practices in exploratory factor analysis: Four recommendations for getting the most from your analysis. Practical Assessment, Research \& Evaluation, 10(7), 1-9.

Devine, A., Fawcett, K., Szúcs, D., \& Dowker, A. (2012). Gender differences in mathematics anxiety and the relation to mathematics performance while controlling for test anxiety. Behavioral and Brain Functions, 8(33), 2-9.

Dowker, A., Sarkar, A., \& Looi, C. Y. (2016). Mathematics anxiety: What have we learned in 60 years? Frontiers in Psychology, 7(508). doi: 10.3389/fpsyg.2016.00508

Eden, C. , Heine, A., \& Jacobs, A. (2013). Mathematics anxiety and its development in the course of formal schooling - A review. Psychology, 4, 27-35. doi: 10.4236/ psych.2013.46A2005

Evans, J. D. (1996). Straightforward Statistics for the Behavioral Sciences. Pacific Grove: Brooks/Cole Publishing.

Ganley, C. M., \& McGraw, A. L. (2016). The development and validation of a Revised Version of the Math Anxiety Scale for Young Children. Frontiers in Psychology, 7(1181). doi: 10.3389/fpsyg.2016.01181

Gierl, M. J., \& Bisanz, J. (1995). Anxieties and attitudes related to mathematics in grades 3 and 6 . The Journal of Experimental Education, 63(2), 139-158. doi: $10.1080 / 00220973.1995 .9943818$

Goetz, T., Bieg, M., Ludtke, O., Pekrun, R., \& Hall, N. C. (2013). Do girls really experience more anxiety in mathematics? Psychological Science, 24(10), 2079-2087. doi: 10.1177/0956797613486989.

Griggs, M. S., Rimm-Kaufman, S. E., Merritt, E. G., \& Patton, C. L. (2013). The responsive classroom approach and fifth grade students' math and science anxiety and self-efficacy. School Psychology Quarterly, 28(4), 360-373. doi: $10.1037 /$ spq0000026

Harari, R. R., Vukovic, R. K., \& Bailey, S. P. (2013). Mathematics anxiety in young children: An exploratory study. The Journal of Experimental Education, 81(4), 538-555. doi: 10.1080/00220973.2012.727888 
Hembree, R. (1990). The nature, effects, and relief of mathematics anxiety. Journal for Research in Mathematics Education, 21(1), 33-46. doi: 10.2307/749455

Hill, F., Mammarella, I. C., Devine, A., Caviola, S., Passolunghi, M. C., \& Szűcs, D. (2016). Math anxiety in primary and secondary school students: Gender differences, developmental changes and anxiety specificity. Learning and Individual Differences, 48, 45-53. doi: 10.1016/j. lindif.2016.02.006

Hu, L., \& Bentler, P. M. (1999). Cutoff criteria for fit indexes in covariance structure analysis: Conventional criteria versus new alternatives. Structural Equation Modeling: A Multidisciplinary Journal, 6(1), 1-55.

Jameson, M. M. (2013). The development and validity of the Children's Anxiety in Math Scale. Journal of Psychoeducational Assessment, 31, 391-395. doi: 10.1177/0734282912470131

Jameson, M. M. (2014). Contextual factors related to math anxiety in second-grade children. The Journal of Experimental Education, 82(4), 518-536. doi: $10.1080 / 00220973.2013 .813367$

Janowicz, J. (2017). Jak statystyka może pomóc w odczytaniu wyników sprawdzianu. Twoja Nowa Era. Magazyn dla nauczycieli matematyki w szkole podstawowej, 17-21. Downloaded from: http://flipbook.nowaera.pl/ dokumenty/Flipbook/Magazyn-Sprawdzian-szostoklasisty-mat/Magazyn-Twoja-nowa-era.pdf [06.01.2020]

Krinzinger, H., Kaufmann, L., \& Willmes, K. (2009). Math anxiety and math ability in early primary school years. Journal of Psychoeducational Assessment, 27(3), 206-225. doi: $10.1177 \% 2 F 0734282908330583$

Kucian, K., Zuber, I., Kohn, J., Poltz, N., Wyschkon, A., Günter, E., \& Von Aster, M. (2018). Relation between mathematical performance, math anxiety, and affective priming in children with and without developmental dyscalculia. Frontiers in Psychology, 9, 263. doi: 10.3389/ fpsyg.2018.00263

Lenhard, W., \& Lenhard, A. (2016). Calculation of effect sizes. Downloaded from: https://www.psychometrica.de/effect_size.html. Dettelbach (Germany): Psychometrica. doi: 10.13140/RG.2.2.17823.92329

Ma, X. (1999). A meta-analysis of the relationship between anxiety toward mathematics and achievement in mathematics. Journal for Research in Mathematics Education, 30(5), 520-540.

Maloney, E. A., Ramirez, G., Gunderson, E. A., Levine, S. C., \& Beilock, S. L. (2015). Integrational effects of parents math anxiety on children's math achievement and anxiety. Psychological Science, 26(9),1480-1488. doi: $10.1177 / 0956797615592630$

Mutlu, Y. (2019). Math anxiety in students with and without math learning difficulties. International Electronic Journal of Elementary Education, 11(5), 471-475.

Núñez-Peña, M. I., Suárez-Pellicioni, M., \& Bono, R. (2016). Gender differences in test anxiety and their impact on higher education students' academic achievement. Procedia - Social and Behavioral Sciences, 228, 154-160. doi: 10.1016/j.sbspro.2016.07.023

Nye, C. D., \& Drasgow, F. (2011). Assessing goodness of fit: simple rules of thumb simply do not work. Organizational Research Methods, 14(3), 548-570.
Putwain, D. W. \& Daniels, R. A. (2010). Is the relationship between competence beliefs and test anxiety influenced by goal orientation? Learning and Individual Differences, 20(1), 8-13. doi: 10.1016/j.lindif.2009.10.006

Stöber, J., \& Pekrun, R. (2004). Advances in test anxiety research. Anxiety, Stress, and Coping, 17(3), 205-211. doi: 10.1080/1061580412331303225

Ramirez, G., Chang, H., Maloney, E. A., Levine, S. C., \& Beilock, S. L. (2016). On the relationship between math anxiety and math achievement in early elementary school: The role of problem solving strategies. Journal of Experimental Child Psychology, 141, 83-100. doi: 10.1016/j. jecp.2015.07.014

Ramirez, G., Gunderson, E. A., Levine, S. C., \& Beilock, S. L. (2013). Math anxiety, working memory, and math achievement in early elementary school. Journal of Cognition and Development, 14(2), 187-202. doi: 10.1080/15248372.2012.664593

Reynolds, C. R., \& Richmond, B. O. (1978). What I think and feel: A revised measure of children's manifest anxiety. Journal of Abnormal Child Psychology, 6(27), 271-280. doi: 10.1007/BF00919131

Revelle, W. (2019). psych: Procedures for Psychological, Psychometric, and Personality Research. Northwestern University, Evanston, Illinois. R package version 1.9.12.

Richardson, F. C., \& Suinn, R. M. (1972). The Mathematics Anxiety Rating Scale: Psychometric data. Journal of Counseling Psychology, 19(6), 551-554.

Rosseel, Y. (2012). lavaan: An R Package for Structural Equation Modeling. Journal of Statistical Software, 48(2), 1-36.

Soni, A., \& Kumari, S. (2017). The role of parental math anxiety and math attitude in their children's math achievement. International Journal of Science and Mathematics Education, 15(2), 331-347. doi: http://dx.doi. org/10.1007\%2Fs10763-015-9687-5

Spence, S. H. (1997). Structure of anxiety symptoms among children: a confirmatory factor-analytic study. Journal of Abnormal Psychology, 106(2), 280-297.

Stark, K. D., \& Laurent, J. (2001). Joint factor analysis of the Children's Depression Inventory and the Revised Children's Manifest Anxiety Scale. Journal of Clinical Child Psychology, 30(4), 552-567. doi: 10.1207/S15374424JCCP3004_11

Szczygieł, M. (2019). How to measure math anxiety in young children? Psychometric properties of the modified Abbreviated Math Anxiety Scale for Elementary Children (mAMAS-E). Polish Psychological Bulletin, 50(4), 303-315. doi: 10.24425/ppb.2019.131003

Szczygieł, M. (2020). When does math anxiety in parents and teachers predict math anxiety and math achievement in elementary school children? The role of gender and grade year. Social Psychology of Education. https://doi. org/10.1007/s11218-020-09570-2

Thomas, G., \& Dowker, A. (2000). Mathematics anxiety and related factors in young children. Paper presented at British Psychological Society Developmental Section Conference, Bristol. 
Van Mier, H. I., Scchleepen, T. M. J., \& Van den Berg, F. C. G. (2019). Gender differences regarding the impact of math anxiety on arithmetic performance in second and fourth graders. Frontiers in Psychology, 9, 2690. doi: 10.3389/fpsyg.2018.02690

Vukovic, R. K., Kieffer, M. J., Bailey, S. P., \& Harari, R. R. (2013). Mathematics anxiety in young children: Concurrent and longitudinal associations with mathematical performance. Contemporary Educational Psychology, 38, 1-10. doi: 10.1016/j.cedpsych.2012.09.001

Wang, Z., Hart, S. A., Kovas, Y., Lukowski, S., Soden, B., Thompson, L. A., ... \& Petrill, S. A. (2014). Who is afraid of math? Two sources of genetic variance for mathematical anxiety. Journal of Child Psychology and Psychiatry, 55(9), 1056-1064. doi: 10.1111/ jcpp.12224

Wren, D. G., \& Benson, J. (2014). Measuring test anxiety in children: Scale development and internal construct validation. Anxiety, Stress, and Coping, 17(3), 227-240. doi: 10.1080/10615800412331292606

Wu, S. S., Barth, M., Amin, H., Melcarne, V., \& Menon, V. (2012). Math anxiety in second and third graders and its relation to mathematics achievement. Frontiers in Psychology, 3(162), 1-11. doi: 10.3389/ fpsyg.2012.00162

Young, C. B., Wu, S. S., \& Menon, V. (2012). The neurodevelopmental basis of math anxiety. Psychological Science, 23(5), 492-501. doi: 10.1177/0956797611429134

Zhang, J., Zhao, N., \& Kong, Q. P. (2019). The relationship between math anxiety and math performance: A meta-analytic investigation. Frontiers in Psychology, 10, 1613. doi: 10.3389/fpsyg.2019.01613 
Appendix

The Math Anxiety Questionnaire for Children (MAQC)

Instruction: I will ask you some questions related to mathematics. Please, answer "yes", "a little" or "no" to my questions.

\begin{tabular}{|c|c|c|c|c|}
\hline 1 & Do you like solving mathematical problems? & Yes & A little & No \\
\hline 2 & Do you like being asked questions during math classes? & Yes & A little & No \\
\hline 3 & Do you like to speak about mathematics? & Yes & A little & No \\
\hline 4 & Are you nervous when you ask questions about mathematics? & Yes & A little & No \\
\hline 5 & Are you nervous at the thought of making a mistake when solving tasks? & Yes & A little & No \\
\hline 6 & Are you afraid of mathematics? & Yes & A little & No \\
\hline 7 & When you are in math class and the teacher says that you will be discussing a new topic, are you nervous? & Yes & A little & No \\
\hline 8 & When you do your homework in mathematics, are you nervous? & Yes & A little & No \\
\hline 9 & When you start to solve a difficult task, are you nervous? & Yes & A little & No \\
\hline 10 & When you solve a task on the blackboard during math class, do you get stressed? & Yes & A little & No \\
\hline 11 & When the teacher explains how to solve a math problem, are you nervous? & Yes & A little & No \\
\hline 12 & When you have to ask your teacher for help because you do not know how to solve a task, are you nervous? & Yes & A little & No \\
\hline
\end{tabular}

Note. Items 1-3 are reversed. Content of items 7, 8, 10, 11, 12 is based on the SEMA, items 1, 2, 5, 6 are inspired by the MASYC, and items 3, 4, 9 are my own proposal. The scale is also available in a 14-item version (author paper). 